\title{
Hypoxia activates signal transducers and activators of transcription 5 (STAT5) and increases its binding activity to the GAS element in mam mary epithelial cells
}

\author{
Youn-Hee Joung ${ }^{1 *}$, Jong-Hwan Park ${ }^{1 *}$ \\ Taekyu Park ${ }^{2}$, Chang-Soo Lee ${ }^{3}$ \\ Oun Hyun Kim ${ }^{4}$, Sang-Kyu $\mathrm{Ye}^{5}$ \\ Un Mok Yang ${ }^{6}$, Kwang Jeon Lee ${ }^{7}$ \\ and Young Mok Yang ${ }^{1,8}$ \\ ${ }^{1}$ Department of Premedical Science \\ College of Medicine and Bio-Food \\ and Drug Research Center \\ ${ }^{2}$ Bio-Food and Drug Research Center \\ ${ }^{3}$ Department of Biomedical Science \\ College of Natural Science and Bio-Food \\ and Drug Research Center \\ ${ }^{4}$ Department of Animal Science \\ College of Natural Science \\ Konkuk University, Chungju 380-701, Korea \\ ${ }^{5}$ Department of Pharmacology \\ College of Medicine, Seoul National University \\ Seoul 110-799, Korea \\ ${ }^{6}$ Woosung Feed Co., LTD. \\ 62-1, Ojeong-dong, Daeduk-gu \\ Daejeon 306-785, Korea \\ ${ }^{7}$ Department of Dairy Science \\ College of Animal Husbandry \\ Konkuk University, Seoul 143-701, Korea \\ ${ }^{8}$ Corresponding Author: Tel, 82-43-840-3754; \\ Fax, 82-43-851-9329; E-mail, ymyang@kku.ac.kr \\ *These authors contributed equally to this work.
}

Accepted 25 July 2003

Abbreviations: DFO, desferrioxamine; EMSA, electrophoretic mobility shift assay; EPO, erythropoietin; GAS, interferon- $\gamma$ activated site; HIF-1, hypoxia-inducible factor-1; PRL, prolactin; ROS, reactive oxygen species; STAT, signal transducers and activators of transcription

\footnotetext{
Abstract

STATs (signal transducers and activators of transcription) are proteins with dual functions: signal transducers in the cytoplasm and transcriptional activators in the nucleus. STAT proteins act as transcription factors activated by phosphorylation on its tyrosine residues upon stimulation by various cytokines. The phosphorylated STAT mole-
}

cules then form homo- or heterodimers through SH2-mediated interaction and translocate into the nucleus to activate the transcription of various target genes. STAT5 recognizes the interferon- $\gamma$ activated site TTCNNNGAA (GAS sequence) in the promoter region of the $\beta$-casein gene. Except for prolactin-dependent $\beta$-casein production in mam$m$ ary gland cells, the biological consequences of STAT5a activation in various systems are not clear. Here we showed that STAT5a was phosphorylated $10 \mathrm{~min}$ after desferrioxamine (DFO) treatment, and reached a maximum induction at 4 $h$ in mammary epithelial cells (HC11) and transfected COS-7 cells. Under hypoxic conditions $(2 \%$ $\mathrm{O}_{2}$ ), a maximal phosphorylation of STAT5a was observed within $6 \mathrm{~h}$. EMSA (electrophoretic mobility shift assay) showed that DFO or hypoxia enhanced the binding activities of STAT5a DNA to $\beta$-casein gene promoter in mammary epithelial cells (HC11) and transfected COS-7 cells. These results showed that DFO or hypoxia induces tyrosine phosphorylation of STAT5a and also increases the binding activity of STAT5a DNA in mammary epithelial cells. Our data suggest that the STAT5 may act as a mediator in hypoxiamediated gene expression.

Keywords: binding activity; desferrioxamine; hypoxia; interferon- $\gamma$ activated site; STAT5a; tyrosine phosphorylation

\section{Introduction}

Hypoxia initiates transcription of a number of gene products that help to sustain the supply of $\mathrm{O}_{2}$ to tissues and to enhance cell survival during severe $\mathrm{O}_{2}$ deprivation. Gene products that augment $\mathrm{O}_{2}$ supply at the tissue level include erythropoietin (Epo), which increases the proliferation of erythrocytes, tyrosine hydroxylase, which is necessary for the synthesis of the neurotransmitter dopamine in the carotid bodies, and the angiogenic factor VEGF (vascular endothelial cell growth factor), which stimulates growth of new capillaries (Chandel et al., 2000; Koh et al., 2002). Oxygen homeostasis is primarily controlled by a cellular oxygen-sensing transcription factor, hypoxia-indu- 
cible factor 1 (HIF-1), which induces the transcription of more than 40 proteins, including VEGF (Choi et al., 2003). Desferrioxamine (DFO), an iron chelator, has been shown to activate HIF-1 in vitro, with kinetics similar to those associated with hypoxia, and to increase expression of HIF-1 target genes, including Epo (Wang and Semenza, 1993). Like hypoxia, DFO stabilizes HIF-1 $\alpha$ subunits, and it has been suggested that the $\mathrm{O}_{2}$-sensing mechanism might involve $\mathrm{O}_{2}$ dependent radical production by a local Fenton reaction (Ren et al., 2000). As we have shown previously, desferrioxamine, mimics hypoxia and a similar oxygen sensor in the hypoxia regulation induces hypoxic condition (Tazuke et al., 1998; Park et al., 2000; Park et al., 2001). The analysis of hypoxiainducible factor-1 (HIF-1) and STAT (signal transducers and activators of transcription) seems a priori less justified because these transcription factors were initially associated with the response to lowered oxygen tension HIF-1 (Choi et al., 2003) and to cytokines STAT5 (Ihle, 1996). But, more recently, both the JAK (janus kinase)-STAT pathway (Simon et al., 1998) and HIF-1 (Chandel et al., 2000) have been shown to be activated by reactive oxygen species (ROS) (Tacchini et al., 2002). Accumulating evidence supports a critical role for oxidative stress in the pathogenesis of atherosclerosis, cancer, and other human diseases (Halliwell, 1989). High levels of reactive oxygen species damage DNA and inactivate proteins, resulting in chronic cellular dysfunction (Shacter et al., 1998). Many cell types have also harnessed ROS, albeit in lower concentrations, as intracellular signaling molecules to mediate growth factor and cytokine responses (Sundaresan et al., 1995). Modulation of growth responses by ROS has been demonstrated in a number of cell types, including vascular smooth muscle cells (VSMCs) (Madamanchi et al., 2001). The signal transducer and activator of transcription (STAT) factors were originally described as growth factor- and interferon-inducible DNA binding complexes (Levy et al., 1988). Subsequently, the STAT factors have been shown to be induced by a wide variety of growth factors and cytokines (Ihle, 1996). These factors participate in the regulation of many genes, including the c-fos protooncogene, caspases, and the cell cycle regulator, which can also respond to oxidative stress (Kumar et al., 1997). The STAT factors are unique, in that they are phosphorylated on tyrosine residues in response to a variety of growth factors and cytokines (Silvennoinen et al., 1993; Shin et al., 2002). On phosphorylation, the STATs dimerize via SH2phosphotyrosine interactions and become competent to bind DNA (Shuai et al., 1994). Before phosphorylation the STATs are found in the cytoplasm and translocate to the nucleus upon activation (Simon et al., 1998). STAT5a was first identified as a DNA binding protein in tissue extracts from lactating mammary gland (Schmitt-Ney et al., 1991; Wakao et al., 1994). Molecular cloning and extensive molecular biological analysis of different tissues at various stages of differentiation revealed that STAT5a was not only expressed in mammary epithelial cells (HC11) and activated by prolactin, but that many hormones, growth factors, and cytokines use STAT5a as a signal transducer (Groner, 2002).

Here we report that DFO or hypoxia activates STAT5 and its binding activities to the GAS sequence in the $\beta$-casein gene promoter in mammary epithelial cells and transfected COS-7 cells.

\section{Materials and Methods}

\section{Materials}

Dulbecco's modified Eagle's medium (DMEM) and RPMI 1640 were purchased from Gibco-BRL (Grand Island, NY). Fetal calf serum (FCS), insulin, epidermal growth factor (EGF), prolactin (PRL) and desferrioxamine (DFO) were obtained from Sigma Chemical Co. (St. Louis, MO). FuGene 6 transfection reagent was purchased from Roche (Basel, Switzerland). AntiSTAT5a and STAT3 antibodies were obtained from Santa Cruz Biotechnology (Santa Cruz, CA). Horseradish peroxidase-conjugated donkey anti-rabbit IgG, enhanced chemiluminescence (ECL) detection kit and $\left[\gamma^{32} \mathrm{P}\right]$ ATP were purchased from Amersham Pharmacia Biotech. (Piscataway, NJ). Restore ${ }^{\mathrm{TM}}$ Western Blot Stripping Buffer was purchased from Pierce (Rockford, IL). Anti-phospho-STAT5a/b (Y694/Y699) antibody was obtained from Upstate Biotechnology (Lake Placid, NY). The oligonucleotide electrophoretic mobility shift assay (EMSA) kit was purchased from Promega (Madison, WI). The oligonucleotide probe (5'-AGATTTCTAGGAATTCAAATC-3') for EMSA analysis was synthesized from Bioneer (Daejeon, Korea).

\section{Expression vector}

The expression vector for mouse STAT5a (pMXSTAT5a; kindly provided by Dr. Koichi Ikuta, Kyoto University, Japan) was constructed as previously described (Onishi et al., 1996). cDNA for mouse STAT5a was inserted into the EcoR I and Not I sites of the pMX vector.

\section{Cell culture}

HC11, mouse mammary epithelial cells, were grown to confluency in RPMI 1640 medium containing 10\% fetal bovine serum, insulin $(5 \mu \mathrm{g} / \mathrm{ml})$, and epidermal growth factor $(10 \mathrm{ng} / \mathrm{ml})$. COS-7 cells were cultured in Dulbecco's modified essential medium containing 
$10 \%$ fetal bovine serum, $2 \mathrm{mM}$ glutamine, and 100 $\mathrm{U} / \mathrm{ml}$ penicillin and streptomycin at $37^{\circ} \mathrm{C}$ in $5 \% \mathrm{CO}_{2}$. At the initiation of each experiment, the cells were resuspended in the medium at a density of $2.5 \times 10^{5}$ cells/ml. For hypoxic conditions, the cells were placed in airtight chambers (NuAire, Plymouth, MN), which were flushed with a $5 \%$ carbon dioxide $/ 95 \%$ nitrogen mixture until the oxygen concentration was $2 \%$.

\section{Transient transfection}

Transfections were performed using the FuGene 6 according to the manufacturer's and the electroporator (Bio-Rad, Hercules, CA). For signal transduction studies, subconfluent COS-7 cells in $35 \mathrm{~mm}$ culture dishes were transfected with $1.3 \mu \mathrm{g}$ of $\mathrm{pMX}$ STAT5a. After $24 \mathrm{~h}$ the cells were starved by serum deprivation overnight.

\section{Total cell lysis and Western blot}

HC11 cells and transiently transfected COS-7 cells were stimulated with DFO time-dependently or under hypoxic conditions $\left(2 \% \mathrm{O}_{2}\right)$. Cells were lysed on ice for $10 \mathrm{~min}$ in RIPA lysis buffer, containing protease and phosphatase inhibitors $(50 \mathrm{mM}$ Tris- $\mathrm{HCl}, \mathrm{pH} 7.5$, $5 \mathrm{mM}$ EDTA, $150 \mathrm{mM} \mathrm{NaCl}, 10 \mathrm{mM}$ sodium phosphate, $10 \mathrm{mM}$ sodium fluoride, $1 \mathrm{mM}$ sodium orthovanadate, $1 \%$ Triton $\mathrm{X}-100,1 \mathrm{mM}$ phenylmethylsulfonylfluoride, and $2 \mu \mathrm{g} / \mathrm{ml}$ leupeptin, $4 \mu \mathrm{g} / \mathrm{ml}$ aprotinin, $1 \mu \mathrm{g} / \mathrm{ml}$ pepstatin). Cells were disrupted by aspiration through a 23 gauge needle, and centrifuged at 15,000 rpm for $10 \mathrm{~min}$ at $4^{\circ} \mathrm{C}$ to remove cellular debris. Protein concentration was measured using the Bradford method (Bradford, 1976). Equal amounts of protein obtained by total lysis were loaded and run on an $8 \%$ SDS-PAGE. The proteins were transferred onto a nitrocellulose membrane. The membrane was blocked for $1 \mathrm{~h}$ in T-TBS buffer $(20 \mathrm{mM}$ Tris- $\mathrm{HCl} \mathrm{pH} 7.6$, $137 \mathrm{mM} \mathrm{NaCl}, 0.1 \times$ Tween 20) plus $5 \%$ non-fat milk, and incubated with a polyclonal anti-STAT5a antibody at room temperature overnight. The membrane was washed three times with T-TBS and incubated with anti-rabbit IgG-conjugated with horseradish peroxidase for $1 \mathrm{~h}$ at room temperature. After washing three times in T-TBS, the membrane was developed employing the enhanced chemiluminescence $(E C L)$ system. Then, the membrane was stripped for $15 \mathrm{~min}$ at room temperature using RestoreTM Western Blot Stripping Buffer (Pierce). Subsequently, the membrane was reprobed with anti-phospho-STAT5a/b (Y694/Y699) antibody (Upstate Biotechnology), which recognizes an epitope that is present in both STAT5 protein.

\section{Electrophoretic mobility shift assay}

STAT5a DNA binding activity was detected using an electrophoretic mobility shift assay (EMSA), in which a labeled double-stranded DNA sequence was used as a DNA probe to bind active STAT5a protein in nuclear extracts. The STAT5a-DNA complex and free DNA were separated using polyacrylamide gel electrophoresis and visualized by autoradiography. The STAT5a binding site (5'-AGATTTCTAGGAATTCAAATC$\left.3^{\prime}\right)$ of the bovine $\beta$-casein promoter was used to design the probe. This oligonucleotide was hybridized with its complementary oligonucleotide (5'-GATTT GAATTCCTAGAAATCT-3') at $45-55^{\circ} \mathrm{C}$ for $10 \mathrm{~min}$ using annealing buffer. The double-stranded DNA probe was end-labeled using $\mathrm{T}_{4}$ polynucleotide kinases and $\left[\gamma_{-}{ }^{32} \mathrm{P}\right]$ ATP and used in all EMSAs. Radiolabeled oligonucleotides were incubated for $20 \mathrm{~min}$ at room temperature in a total volume of $20 \mu \mathrm{l}$ containing 2.5-5.0 $\mu \mathrm{g}$ of nuclear protein, and radiolabeled oligonucleotide. Electrophoresis through a $6 \%$ polyacrylamide gel was carried out in $0.5 \times$ TBE buffer for $1.2 \mathrm{~h}$ at $300 \mathrm{~V}$. The gel was then dried and exposed to X-ray film. Sequence specificity of nuclear protein binding to all oligonucleotides was confirmed by competition studies in which nuclear extracts were incubated for $5 \mathrm{~min}$ at room temperature with a 50 fold molar excess unlabeled competitor oligonucleotide before the addition of radiolabeled oligonucleotide. STAT5a proteins bound to the GAS element were identified by supershift with antibodies specific for STAT5a (Santa Cruz Biotechnology). Nuclear proteins were incubated with $1 \mu \mathrm{g} / \mu \mathrm{l}$ of the anti-STAT5a polyclonal antibody for $20 \mathrm{~min}$ on ice before the addition of radiolabeled oligonucleotide.

\section{Results and Discussion}

\section{DFO induces tyrosine phosphorylation of STAT5a in mammary epithelial cells}

To confirm the activation of STAT5a by DFO, we examined the tyrosine phosphorylation state in tyrosine-694 of STAT5a with a phosphotyrosine-specific antibody (anti-phospho-STAT5a/b) by Western blotting after DFO treatment. Phosphorylation of tyrosine-694 is known to be responsible for STAT5a dimerization and activation of DNA binding (Zhong et al., 1994). We investigated the tyrosine phosphorylation of STAT5a in DFO-treated, transfected COS-7 cells and HC11 cells.

For this purpose, the proteins were analyzed by sodium dodecyl sulfate (SDS)-gel electrophoresis and visualized with a phosphotyrosine-specific antibody (anti-phospho-STAT5a/b). As shown in Figure $1 \mathrm{~A}$ and 1B, STAT5 was phosphorylated $10 \mathrm{~min}$ after DFO 


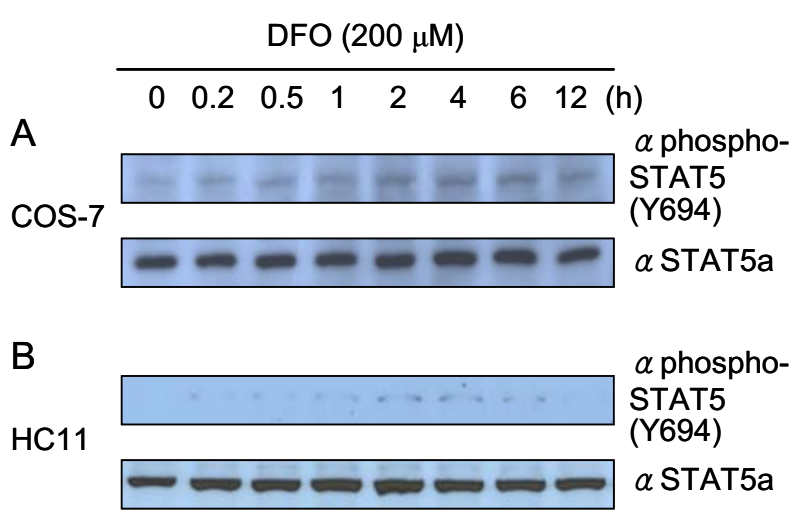

Figure 1. Time course phosphorylation of STAT5a in transfected COS-7 cells and HC11 cells in response to desferrioxamine (DFO). Cells were treated with DFO $(200 \mu \mathrm{M})$ for various durations $(0$, $0.2,0.5,1,2,4,6$, and $12 \mathrm{~h}$ ). Cell lysates were separated on $8 \%$ SDS-PAGE and transferred to nitrocellulose membrane. The membrane was blotted with the anti-phospho-STAT5a/b, then stripped and reprobed with the anti-STAT5a antibody. (A) Transfected COS-7 cells, (B) Mammary epithelial cells (HC11). Y694, tyrosine-694.

treatments, and the STAT5a phosphorylation was sustained for $6 \mathrm{~h}$. The tyrosine phosphorylation of STAT5a by DFO treatments in HC11 cells was activated and reached maximum after 2 to $4 \mathrm{~h}$. Whereas maximal phosphorylation of STAT5a in COS-7 cells was observed within $4 \mathrm{~h}$ (Figure 1A). The tyrosine phosphorylation of STAT5a was strongly downregulated after $6 \mathrm{~h}$ (Figure 1B). These results indicate that DFO induces tyrosine phosphorylation of STAT5 in mammary epithelial cells. STAT5 was originally identified as mammary gland factor (MGF), a prolactin target gene, by the Groner laboratory (Wakao et al., 1994). Other investigations by several laboratories demonstrated that STAT5 was actually expressed as two co-localized genes, STAT5a and STAT5b, with high similarity (Mui et al., 1995). Furthermore, a multitude of cytokines activate STAT5 including IL-2 (Lin et al., 1996), LI-3 (Mui et al., 1995), IL-5 (Mui et al., 1995), IL-7 (Ye et al., 1999; Ye et al., 2001), IL-9 (Demoulin et al., 1996), IL-15 (Johnston et al., 1995), G-CSF (Nicholson et al., 1996), GM-CSF (Mui et al., 1995), EPO (Damen et al., 1995), growth hormone (Goulleux et al., 1995) and prolactin (Wakao et al., 1994; Halupa and Barber, 2000).

\section{Hypoxia induces tyrosine phosphorylation of STAT5a in mammary epithelial cells}

We investigated the tyrosine phosphorylation of STAT5a under hypoxic conditions in transfected COS-7 and $\mathrm{HC} 11$ cells at 1 and $6 \mathrm{~h}$. Under hypoxic conditions, the tyrosine phosphorylation of STAT5a reached a maximum at $6 \mathrm{~h}$ in two cell lines (Figure $2 \mathrm{~A}$ and $2 \mathrm{~B}$ ). These results show that STAT5a phosphorylation is

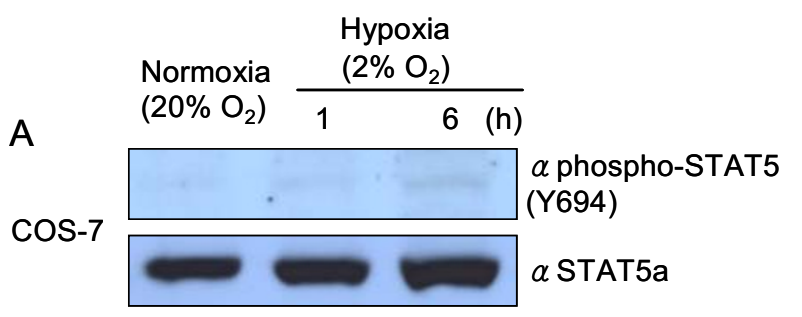

B

$\mathrm{HC} 11$
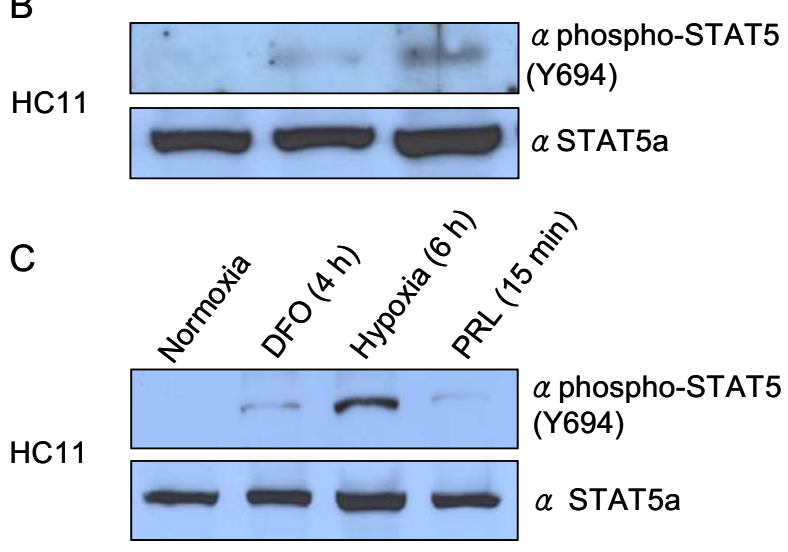

Figure 2. (A), (B) Time course phosphorylation of STAT5a in transfected COS-7 cells and $\mathrm{HC11}$ cells in response to hypoxia. Cells were treated with hypoxic conditions $\left(2 \% \mathrm{O}_{2}\right)$ for various durations $(0,1$, and $6 \mathrm{~h})$. (C) Comparison of STAT5a tyrosine phosphorylation from $\mathrm{HC} 11$ cells under normoxia, DFO (desferrioxamine) treatment, hypoxia $\left(2 \% \mathrm{O}_{2}\right)$ or PRL (prolactin) treatment. Cell lysates were separated on $8 \%$ SDS-PAGE and transferred to nitrocellulose membrane. The membrane was blotted with the anti-phospho-STAT5$a / b$, then stripped and reprobed with the anti-STAT5a antibody. Y694, tyrosine-694.

time-dependently up-regulated by hypoxia. To compare the expression level of STAT5a protein by DFO, hypoxia or PRL in HC11 cells, Western blot analysis was performed with protein extracts obtained from untreated (normoxic condition), DFO $(4 \mathrm{~h})$-, hypoxic condition (6 h)- and PRL (15 min)-treated for HC11 cells (Figure 2C). The figure showed that hypoxia induced the higher level of STAT5a tyrosine phosphorylation more than PRL or DFO. Recent work in many laboratories has shown the activation of critical signal transduction pathways by ROS, such as the NFK-B, the JNK-AP-1, and the Ras/Rac mitogen-activated protein kinase pathways (Irani et al., 1997). Although the STAT family of transcription factors is known to be activated by most cytokines and growth factors, we have shown that, in addition to these agonists, STAT family members can also be activated by oxidative stress (Simon et al., 1998). In particular, we have shown in transfected COS-7 cells and $\mathrm{HC} 11$ cells that the activation of STAT5a in response to hypoxia occurs within hours and is independent of new protein synthesis. 


\section{DFO increases STAT5a DNA binding activity in mammary epithelial cells}

The JAK-STAT signal transduction pathway influences normal cell survival and growth mechanisms and may contribute to oncogenic transformation. Activated STATS form dimers, translocate to the nucleus, bind to specific response elements in promoters of target genes, and transcriptionally activate these genes. Mammary gland factor (MGF; STAT5a) recognizes the PRL response element TTCNNNGAA (GAS sequence) in the promoter region of the $\beta$-casein (Liu et al., 1995).

We studied the DNA-binding capacity of STAT5a by an electrophoretic mobility shift assay (EMSA). Expression of the $\beta$-casein gene, which contains the consensus sequence for this STAT5a in its promoter, has been assessed by the amount of the corre-
A
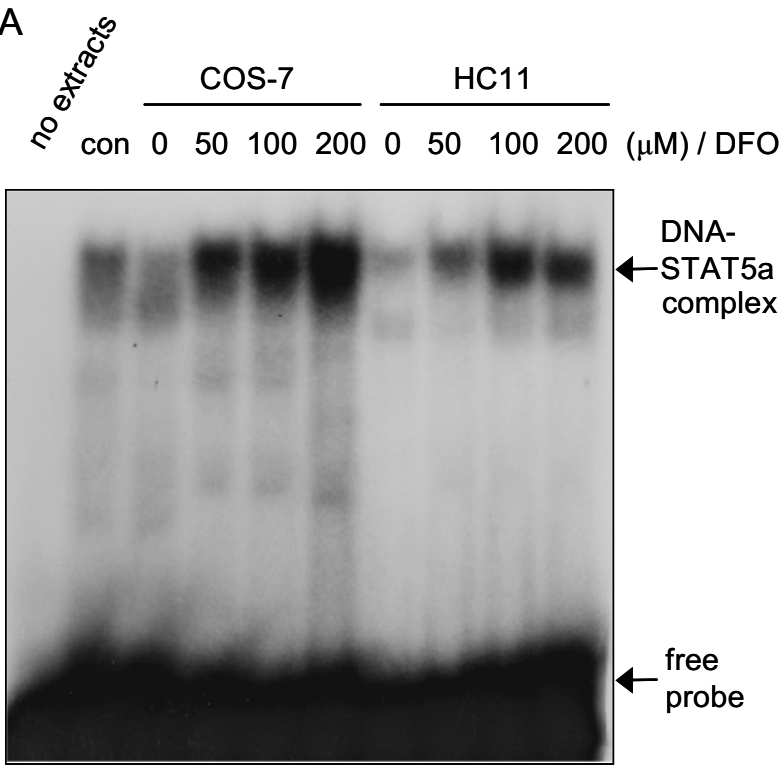

C

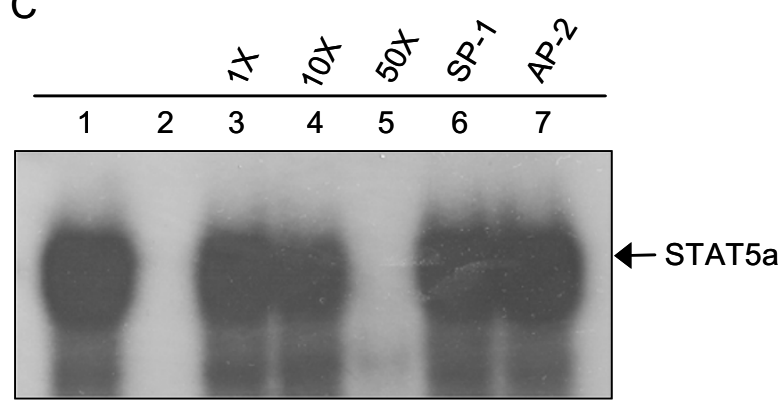

B
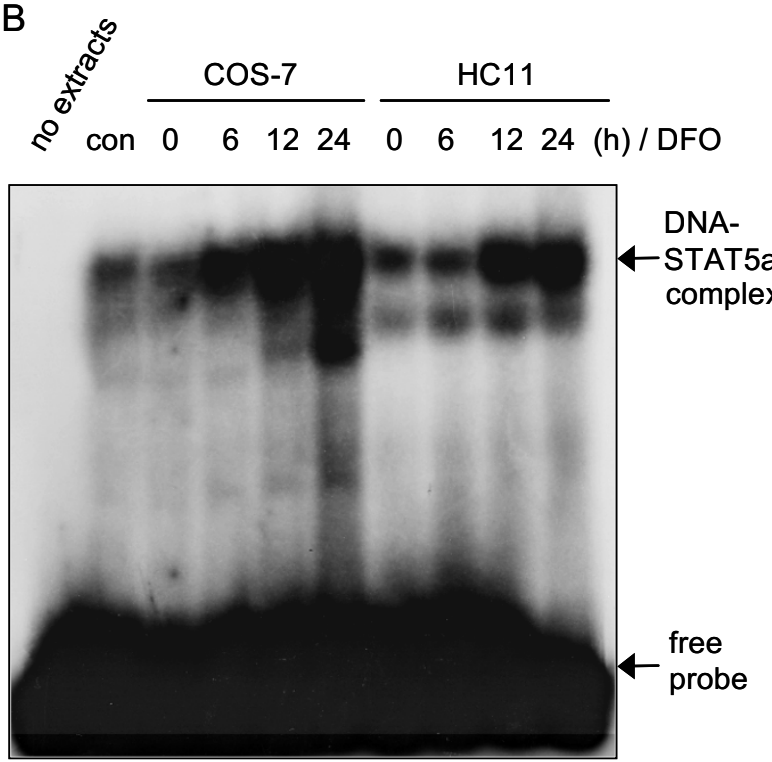

D

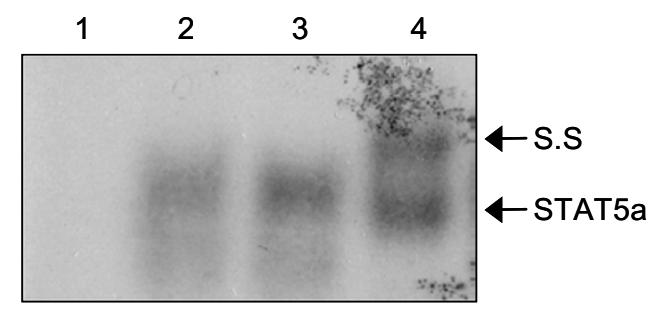

Figure 3. (A) DNA-binding activities of STAT5a in transfected COS-7 cells and HC11 cells treated with DFO (desferrioxamine) concentraion $(\mu \mathrm{M})$ detected by EMSA. Nuclear extracts were prepared and analyzed in bandshift assays using ${ }^{32} \mathrm{P}$-labeled $\beta$-casein promoter STAT5a binding site as a probe. No extracts, negative control. Con, positive control protein (3rd lane) plus anti-STAT5a antibody. The resulting complexes were electrophoresed in $6 \%$ non-denaturing gel. (B) DNA-binding activities of STAT5a in transfected COS-7 cells and HC11 cells treated with DFO $(200 \mu \mathrm{M})$ by time course $(\mathrm{h})$, detected by EMSA. Nuclear extracts were prepared and analyzed in bandshift assays using ${ }^{32}$ P-labeled $\beta$-casein promoter STAT5a binding site as a probe. No extracts, negative control. Con, positive control protein (3rd lane) plus anti-STAT5a antibody. The resulting complexes were electrophoresed in $6 \%$ non-denaturing gel. (C) The competitor in EMSA analysis was unlabeled $\beta$-casein consensus nucleotide and the nonspecific one were unlabeled SP-1, and AP-2 consensus nucleotides. Lane 1: no competitor. Lane 2: no nuclear protein. Lane 3: 1-fold molar excess of competitor. Lane 4: 10-fold molar excess of competitor. Lane 5: 50-fold molar excess of competitor. Lane 6: 100-fold molar excess of noncompetitor (SP-1). Lane 7: 100-fold molar excess of noncompetitor (AP-2). The resulting complexes were electrophoresed in $6 \%$ non-denaturing gel. (D) To demonstrate the identity of the complexes, anti-STAT5a antibody was preincubated with the extracts for $30 \mathrm{~min}$ prior to the binding reaction with the labeled oligomer, as indicated (S.S, super shift). Nuclear extracts were isolated from COS-7 cells treated with DFO, and $5 \mu \mathrm{g}$ of nuclear protein were used in EMSA analysis. Lane 1: no nuclear protein. Lane 2: without antibody. Lane 3: STAT3 antibody. Lane 4: STAT5a antibody. The resulting complexes were electrophoresed in $6 \%$ non-denaturing gel. 
sponding proteins (Tacchini et al., 2002). To test the hypothesis that DFO increases STAT5a binding activity, we examined the DNA-binding activities of STAT5a after dose- and time-dependent DFO treatments in transfected COS-7 and HC11 cells. The results showed that DFO enhanced STAT5a protein expression dose- and time-dependent manner (Figure $3 \mathrm{~A}$ and $3 \mathrm{~B}$ ). In the DFO dose-response analysis, when compared with untreated cells, STAT5a DNA binding activities were markedly increased in DFO-treated two cell lines treated with DFO (Figure $3 \mathrm{~A}$ ). As shown in Figure 3B, STAT5a DNA binding activities were time-dependently up-regulated by DFO treatments in two cell lines. To investigate the binding specificity of the protein complexes, competition EMSAs with unlabeled $\beta$ - casein and nonspecific SP-1, and AP-2 consensus nucleotides as probe were used with nuclear extracts from DFO-treated COS-7 cells transfected with a STAT5a expression vector and $\mathrm{HC} 11$ cells. Figure $3 \mathrm{C}$ shows that a $\beta$-casein consensus element efficiently inhibited binding, whereas a nonspecific SP-1, or AP-2 oligonucleotide in molar excess did not compete for binding. To further identify the protein composition of the STAT5a-binding complex, polyclonal antibodies to STAT5a, and STAT3 were used in a supershift analysis with nuclear extracts from DFO-treated COS7 cells. As shown in Figure 3D, the polyclonal antibody to STAT5a shifted the complex, whereas STAT3 had no effect.

\section{Hypoxia increases STAT5a DNA binding activity in mammary epithelial cells}

Our results also indicate that hypoxic conditions increase STAT5a DNA binding activity to the GAS sequence in the $\beta$-casein gene promoter in transfected COS-7 cells and mammary epithelial cells (Figure 4). DFO or hypoxia appears to induce the DNA binding activity of STAT5a via a similar mechanism to prolactin, requiring the phosphorylation of tyrosine-694. To test the hypothesis that hypoxia activates STAT5a, we examined the DNA-binding activity of STAT5a to the $\beta$-casein promoter under hypoxic conditions $(2 \%$ $\mathrm{O}_{2}$ ). Transiently transfected COS-7 cells and $\mathrm{HC} 11$ cells were stimulated under normoxic conditions $(20 \%$ $\mathrm{O}_{2}$ ), desferrioxamine (DFO) or hypoxic conditions ( $2 \%$ $\mathrm{O}_{2}$ ). The results showed that both DFO and hypoxia increased STAT5a DNA-binding activities in transfected COS-7 and HC11 cells (Figure 4).

STAT5 knockout mice have deficiencies in reproduction (Darnell, 1997; Simon et al., 1998). The phenotypes of STAT5a and STAT5b individual knockouts reveal the importance of STAT5a in breast development and lactation and the importance of STAT5b in the development of sexually dimorphic patterns of gene expression within the liver. In addition

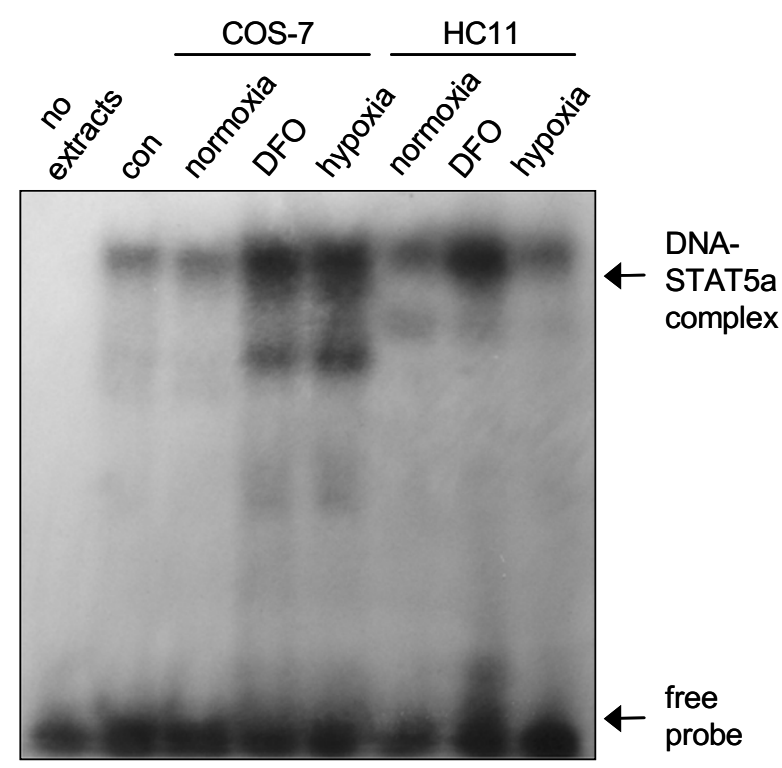

Figure 4. DNA-binding activities of STAT5a in transfected COS-7 cells and $\mathrm{HC} 11$ cells under normoxia $\left(20 \% \mathrm{O}_{2}\right)$, DFO treatment, and hypoxia $\left(2 \% \mathrm{O}_{2}\right)$, detected by EMSA. Nuclear extracts were prepared and analyzed in bandshift assays using ${ }^{32}$-labeled $\beta$ casein promoter STAT5a binding site as a probe. No extracts, negative control. Con, positive control protein (3rd lane; COS-7 normoxia) plus anti-STAT5a antibody. The resulting complexes were electrophoresed in $6 \%$ non-denaturing gel.

to these phenotypes, STAT5a/b double knockouts are abnormal in their $T$ cell and $B$ cell development. Beyond these various roles in normal cellular and physiological processes, the STAT proteins are now known to participate in cellular transformation and oncogenesis. We consider the evidence implicating these molecules, particularly STATs 1,3 , and 5 , in tumor formation and progression.

STAT5 is also commonly found to be constitutively activated in certain malignancies, especially leukemias and lymphomas. The expression of fusion proteins that cause heightened or unrestrained JAK2, PDGF-R (platelet derived growth factor-receptor), or $\mathrm{ABL}$ (Abelson) signaling can lead to the constitutive activation of STAT5 (Sexl et al., 2000). It is important to recognize that STATs, including STAT5a, can be persistently activated under various circumstances in which cellular transformation is not the ultimate phenotype in macrophages within an inflamed joint, for example, and in neuronal hypoxia (Bromberg, 2002).

In summary, this study demonstrates for the first time that DFO or hypoxia induces tyrosine phosphorylation of STAT5a and then increases the STAT5a DNA binding activity to the GAS element in mammary epithelial cells. Our data suggest that the STAT5 may act as a mediator in hypoxia-mediated gene expression. 


\section{Acknowledgment}

We especially thank Dr. Koichi Ikuta at Institute for Virus Research, Kyoto University, Japan for the kind provision of the STAT5a expression vector for mouse. We also thank Dr. Changil Kim, and Dr. Young Tae Ro at Konkuk University for helpful comments. This work was supported by Konkuk University in 2002, and was partially supported by the Ministry of Science and Technology through the Bio-Food and Drug Research Center at Konkuk University and Ministry of Agriculture and Forestry special grants research program in Korea.

\section{References}

Bradford MM. A rapid and sensitive method for the quantitation of microgram quantities of protein utilizing the principle of protein-dye binding. Anal Biochem 1976;72:248-54

Bromberg J. Stat proteins and oncogenesis. J Clin Invest 2002;109:1139-42

Chandel NS, McCintock DS, Feliciano CE, Wood TM, Melendez JA, Rodriguez AM, Schumacker PT. Reactive oxygen species generated at mitochondrial complex III stabilize hypoxia-inducible factor-1 $\alpha$ during hypoxia. J Biol Chem 2000;275:25130-8

Choi KS, Bae MK, Jeong JW, Moon HE, Kim KW. Hypoxiainduced angiogenesis during carcinogenesis. J Biochem Mol Biol 2003;36:120-7

Damen JE, Wakao H, Miyajima A, Krosl J, Humphries RK, Cutler RL, Krystal G. Tyrosine 343 in the erythropoietin receptor positively regulates erythropoietin-induced cell proliferation and Star5 activation. EMBO J 1995;14:5557-68

Darnell JE Jr. STATs and gene regulation. Science 1997; $277: 1630-5$

Demoulin JB, Uyttenhove C, Van Roost E, DeLestre B, Donckers D, Van Snick J, Renauld JC. A single tyrosine of the interleukin-9 (IL-9) receptor is required for STAT activation, antiapoptotic activity, and growth regulation by IL-9. Mol Cell Biol 1996;16:4710-6

Gouilleux F, Pallard C, Dusanter-Fourt I, Wakao H, Haldosen LA, Norstedt G, Levy D, Groner B. Prolactin, growth hormone, erythropoietin and granulocyte-macrophage colony stimulating factor induce MGF-Stat5 DNA binding activity. EMBO J 1995;14:2005-13

Groner B. Transcription factor regulation in mammary epithelial cells. Domest Anim Endocrinol 2002;23:25-32

Halliwell B. Free radicals, reactive oxygen species and human discase: a critical evaluation with special reference to atheroselerosis. $\mathrm{Br} J$ Exp Pathol 1989;70:737-57

Halupa A, Barber DL. Specificity in JAK-STAT signalling. In Protein Kinase Functions (Woodgett J), 2000;194-245, Oxford, New York, NY

Ihle JN. STATs: signal transducers and activators of transcription. Cell 1996;84:331-4
Irani K, Xia Y, Zweier JL, Sollott SJ, Der CJ, Fearon ER, Sundaresan M, Finkel T, Goldschmidt-Clermont PJ. Mitogenic signaling mediated by oxidants in Ras-transformed fibroblasts. Science 1997;275:1649-52

Johnston JA, Bacon CM, Finbloom DS, Rees RC, Kaplan D, Shibuya K, Ortaldo JR, Gupta S, Chen YQ, Giri JD, O'Shea JJ. Tyrosine phosphorylation and activation of STAT5, STAT3, and Janus kinases by interleukin 2 and 15. Proc Natl Acad Sci USA 1995;92:8705-9

Koh GY, Kim IJ, Kwak HJ, Yun MJ, Leem JC. Biomedical significance of endothelial cell specific growth factor, angiopoietin. Exp Mol Med 2002;34:1-11

Kumar A, Commane M, Flickinger TW, Horvath CM, Stark GR. Defective TNF- $\alpha$-induced apoptosis in STAT-null cells due to low constitutive levels of caspases. Science 1997; 278:1630-2

Levy DE, Kessler DS, Pine R, Reich N, Darnell JE Jr. Interferon-induced nuclear factors that bind a shared promoter element correlate with positive and negative transcriptional control. Genes Dev 1988;2:383-93

Lin JX, Mietz J, Modi WS, John S, Leonard WJ. Cloning of human Stat5B. Reconstitution of interleukin-2-induced Stat5A and Stat5B DNA binding activity in COS-7 cells. J Biol Chem 1996;271:10738-44

Liu X, Robinson GW, Gouilleux F, Groner B, Hennighausen L. Cloning and expression of Stat5 and an additional homologue (Stat5b) involved in prolactin signal transduction in mouse mammary tissue. Proc Natl Acad Sci USA 1995; 92:8831-5

Madamanchi NR, Li S, Patterson C, Runge MS. Reacive oxygen species regulate heat-shock protein 70 via the Jak/Stat pathway. Arterioscler Thromb Vase Biol 2001;21:321-6

Mui AL, Wakao H, O'Farrell AM, Harada N, Miyajima A. Interleukin-3, granulocyte-macrophage colony stimulating factor and interleukin-5 transduce signals through two STAT5 homologs. EMBO J 1995;14:1166-75

Nicholson SE, Starr R, Novak U, Hilton DJ, Layton JE. Tyrosine residues in the granulocyte colony-stimulating factor (G-CSF) receptor mediate G-CSF-induced differentiation of murine myeloid leukemic (M1) cells. J Biol Chem 1996;271: 26947-53

Onishi M, Kinoshita S, Morikawa $Y$, Shibuya A, Phillips J, Lanier LL, Gorman DM, Nolan GP, Miyajima A, Kitamura T. Applications of retrovirus-mediated expression cloning. Exp Hematol 1996;24:324-9

Park JH, Lee HY, Roh SC, Kim HY, Yang YM. Screening of differentially expressed genes by desferrioxamine or ferric ammonium citrate treatment in HepG2 cells. J Biochem Mol Biol 2000;33:396-401

Park JH, Park TK, Kim HY, Yang YM. The IGFBP-1 mRNA expression in HepG2 cells is affected by inhibition of heme biosynthesis. J Biochem Mol Biol 2001;34:385-9

Ren X, Dorrington KL, Maxwell PH, Robbins PA. Effects of desferrioxamine of serum erythropoietin and ventilatory sensitivity to hypoxia in humans. J Appl Physiol 2000;89:680-6

Schmitt-Ney M, Doppler W, Ball R, Groner B. Beta-casein gene promoter activity is regulated by the hormone-mediated 
relief of transcriptional repression and a mammary gland specific nuclear factor. Mol Cell Biol 1991;11:3745-55

Sexl V, Piekorz R, Moriggl R, Rohrer J, Brown MP, Bunting KD, Rothammer K, Roussel MF, Khle JN. Stat5a/b contribute to interleukin 7-induced B-cell precursor expansion, but abland bcr/abl-induced transformation are independent of stat5. Blood 2000;96:2277-83

Shacter E, Beecham EJ, Covey JM, Kohn KW, Potter M. Activated neutrophils induce prolonged DNA damage in neighboring cells. Carcinogenesis 1998;9:2297-304

Shin SY, Yoon SC, Kim YH, Kim YS, Lee YH. Phosphorylation of glycogen synthase kinase- $3 \beta$ at serine- 9 by phospholipase $\mathrm{C} \gamma 1$ through protein kinase $\mathrm{C}$ in rat $3 Y 1$ fibroblasts. Exp Mol Med 2002;34:444-50

Shuai K, Horvath CM, Huang LH, Qureshi SA, Cowburn D, Darnell JE Jr. Interferon activation of the transcription factor Stat91 involves dimerization through SH2-phosphotyrosyl peptide interactions. Cell 1994;76:821-8

Silvennoinen $\mathrm{O}$, Schindler C, Schlessinger J, Levy DE. Rasindependent growth factor signaling by transcription factor tyrosine phosphorylation. Science 1993;261:1736-9

Simon AR, Rai U, Fanburg BL, Cochran BH. Activation of the JAK-STAT pathway by reactiv oxygen species. Am J Physiol 1998;275:C1640-52

Sundaresan M, Yu Z-X, Ferrans VJ, Irani K, Finkel T. Requirement for generation of $\mathrm{H}_{2} \mathrm{O}_{2}$ for platelet derived growth factor signal transduction. Science 1995;270:296-9
Tacchini L, Fusar-Poli D, Bernelli-Zazzera A. Activation of transcription factors by drugs inducing oxidative stress in rat liver. Biochem Pharmacol 2002;63:139-48

Tazuke SL, Mazure NM, Sugawara J, Carland G, Faessen GH, Suen LF, Irwin JC, Powell DR, Giaccia AJ, Giudice LC. Hypoxia stimulates insulin-like growth factor binding protein 1 (IGFBP-1) gene expression in HepG2 cells: a possible model for IGFBP-1 expression in fetal hypoxia. Proc Natl Acad Sci USA 1998;95:10188-93

Wakao H, Gouilleux F, Groner B. Mammary gland factor (MGF) is a novel member of the cytokine regulated transcription factor gene family and confers the prolactin response. EMBO J 1994:13:2182-91

Wang GL, Semenza GL. Desferrioxamine induces erythroietin gene expression and hypoxia-inducible factor 1 DNA binding activity: implications for models of hypoxia signal transduction. Blood 1993;82:3610-5

Ye SK, Maki K, Kitamura T, Sunaga S, Akashi K, Domen $\mathrm{J}$, Weissman IL, Honjo T, Ikuta K. Induction of germline transcription in the TCR-gamma locus by Stat5: implications for accessibility control by the IL-7 receptor. Immunity 1999;11: 213-23

Ye SK, Agata Y, Lee HC, Kurooka H, Kitamura T, Shimizu A, Honjo T, Ikuta K. The IL-7 Receptor controls the accessibility of the TCR $\gamma$ locus by Stat5 and histone acetylation. Immunity 2001;15:813-23

Zhong Z, Wen Z, Darnell JE Jr. Stat3: an STAT family member activated by tyrosine phosphorylation in response to epidermal growth factor and interleukin-6. Science 1994;264: 95-8 